\title{
AVALIAÇÃO ESCOLAR E AS CRIANÇAS COM DEFICIÊNCIAS: DE POLÍTICAS EXCLUDENTES A APROXIMAÇÕES INCLUSIVAS
}

\author{
EVALUACIÓN ESCOLAR Y NIÑOS CON DISCAPACIDADES: DESDE POLÍTICAS \\ EXCLUSIVAS HASTA ENFOQUES INCLUSIVOS
}

\author{
SCHOOL EVALUATION AND CHILDREN WITH DISABILITIES: FROM \\ EXCLUSIONARY POLICIES TO INCLUSIVE APPROACHES
}

\author{
Janine Cecília Gonçalves PEIXOTO ${ }^{1}$ \\ Olenir Maria MENDES ${ }^{2}$
}

\begin{abstract}
RESUMO: A avaliação escolar para as crianças com deficiências é um desafio para os profissionais da educação. Neste sentido, o presente trabalho tem por objetivo apresentar alguns dos resultados de pesquisa de mestrado cujo título é "A avaliação escolar no processo educacional de crianças com deficiências na perspectiva de docentes do ensino fundamental". Objetivamos compreender aspectos em que a avaliação escolar se aproxima da avaliação formativa na perspectiva de docentes do ensino fundamental. Para essa pesquisa de abordagem qualitativa utilizamos como metodologia de investigação a análise de conteúdo e técnica de grupo focal. Nos diálogos das professoras pudemos entender o quanto a escola permanece em uma lógica excludente e por essa razão é importante resistir e optar por propostas de trabalho avaliativo que se aproximem de princípios inclusivos. Concluímos que, as professoras organizam o trabalho pedagógico para as crianças com deficiências em consonância com os princípios da avaliação formativa.
\end{abstract}

PALAVRAS-CHAVE: Avaliação formativa. Crianças. Deficiências.

RESUMEN: La evaluación escolar para niños con discapacidad es un desafío para los profesionales de la educación. En este sentido, el presente trabajo tiene como objetivo presentar algunos de los resultados de la investigación de maestría cuyo título es "La evaluación escolar en el proceso educativo de los niños con discapacidad desde la perspectiva de los profesores de educación básica". Nuestro objetivo es comprender aspectos de la evaluación escolar cercanos a la evaluación formativa desde la perspectiva de los profesores de primaria. Para esta investigación con enfoque cualitativo, utilizamos la técnica de análisis de contenido y grupos focales como metodología de investigación. En los diálogos de los docentes pudimos entender cuánto queda la escuela en una lógica excluyente y por eso es importante resistir y elegir propuestas de trabajo evaluativo que se acerquen a principios inclusivos. Concluimos que los profesores organizan el trabajo pedagógico para niños con discapacidad de acuerdo con los principios de la evaluación formativa.

PALABRAS CLAVE: Evaluación formativa. Niños. Deficiencias.

\footnotetext{
${ }^{1}$ Universidade Federal de Uberlândia (UFU), Uberlândia - MG - Brasil. Mestranda no Programa de Pósgraduação em Educação. ORCID: https://orcid.org/0000-0003-1576-6810. E-mail: janinecgp@gmail.com ${ }^{2}$ Universidade Federal de Uberlândia (UFU), Uberlândia - MG - Brasil. Professora no Programa de PósGraduação em Educação. Doutorado em Educação (USP). ORCID: https://orcid.org/0000-0002-8607-2632. Email: olenir@ufu.br
}

RPGE-Revista on line de Política e Gestão Educacional, Araraquara, v. 25, n. 1, p. 06-18, jan./abr. 2021. DOI: https://doi.org/10.22633/rpge.v25i1.14113

e-ISSN:1519-9029 
ABSTRACT: School evaluation for children with disabilities is a challenge for education professionals. In this sense, this work aims to present some of the results of master's research whose title is "School evaluation in the educational process of children with disabilities from the perspective of elementary school teachers". We aim to understand aspects in school evaluation that are close to formative evaluation from the perspective of elementary school teachers. For this qualitative approach research, we use as methodology the analysis of content and focus group technique. In the teachers' dialogues we were able to understand to what extent the school remains in an excluding logic and for due to this is important to resist and opt for proposals of evaluative work that are close to inclusive principles. We concluded that the teachers organize the pedagogical work for children with disabilities in accordance with the principles of formative evaluation.

KEYWORDS: Formative evaluation. Children. Disabilities.

\section{Introdução}

A avaliação escolar é uma temática complexa e constantemente estudada por profissionais da educação, principalmente quando há intenção de promover aprendizagens significativas às crianças. Atualmente a escola não tem garantido aprendizagem significativa a todos/as, pois as condições socioeconômicas e culturais da grande maioria dos estudantes não possibilitam o rendimento esperado ou imposto pela lógica capitalista (FREITAS, 2003). A escola é excludente e perpetua a exclusão sociocultural das pessoas. Mantoan nos esclarece que: "A exclusão escolar manifesta-se das mais diversas e perversas maneiras, e quase sempre o que está em jogo é a ignorância do aluno diante dos padrões de cientificidade do saber escolar" (MANTOAN, 2003, p. 13).

Entendemos que as diferenças e a diversidade inerentes à heterogeneidade humana nem sempre alcançam os requisitos homogêneos exigidos pela organização do sistema escolar atual. E é neste aspecto que concentramos nossos estudos.

Do mesmo modo, a temática sobre inclusão, especialmente quando se trata de crianças com deficiência, é ponto de debates e discussões nas instituições escolares. A inclusão escolar é relativamente recente no contexto das escolas regulares e organizar saberes, metodologias e procedimentos que auxiliam os/as professore/as nos processos de ensino, aprendizagem e avaliação das crianças com deficiência, não é uma tarefa fácil. Rodrigues (2006) indica que a LDB 9394/96 evidencia que vivemos em um momento de transição na área de educação especial, em que serviços, modos de organização pedagógicos e ajustes para atender as crianças com deficiência se fazem tão necessário. 
Acreditamos que compreender os desafios de práticas avaliativas para as crianças com deficiências é estudar as condições, o desenvolvimento, as limitações e as possibilidades que favoreçam a aprendizagem.

É a favor de uma escola que repense a função social, a organização didáticopedagógica, a concepção de avaliação, o modo como percebe os/as estudantes no contexto educativo, sociais, econômicos e culturais que procuramos pensar e refletir. A partir disso, atentamos para investigar como esses aspectos relacionados à avaliação, com foco na avaliação formativa e o modo como as crianças com deficiências são avaliadas nos espaços escolares, podem favorecer a todos/as na comunidade escolar: profissionais, professores/as, estudantes e familiares.

Estudar a avaliação formativa é uma escolha; é confirmar a busca por práticas pedagógicas avaliativas que atendam propostas mais humanizadoras, inclusivas e progressistas (FREITAS, 2003). Nesse quesito, a avaliação formativa, apresenta princípios de coletividade e inclusão, além de preocupação com a qualidade do ensino e aprendizagem dos/as estudantes, com ou sem deficiência. Por esse motivo a avaliação formativa é o foco teórico desta pesquisa.

Avaliação formativa significa estar a favor de uma concepção da e para as aprendizagens, que oportuniza possibilidades construtivas, interativas no processo cognoscente, e no trabalho pedagógico o ensino, a avaliação e aprendizagem não se desassociam, mas são parte intrínseca de uma ação conjunta, ensino-aprendizagem-avaliação. (VILLAS BOAS, 2011).

Assim sendo, esta pesquisa objetiva compreender de que modo as crianças com deficiência são atendidas por práticas avaliativas que favoreçam a inclusão, levando em conta processos de ensino, aprendizagem e avaliação.

\section{Os caminhos teóricos e metodológicos da pesquisa}

Apresentamos neste artigo apenas um recorte da pesquisa de mestrado cujo foco foi analisar a avaliação escolar no processo educativo das crianças com deficiências sob a perspectiva de professoras do ensino fundamental. Para desenvolver tal pesquisa, optamos por um percurso metodológico de abordagem qualitativa, além de utilizar a técnica de Grupo Focal (GONDIN, 2003) que possibilitou a coleta de informações. 
Os participantes foram professores e professoras que atuam no Ensino Fundamental das escolas públicas do município de Uberlândia. E para o tratamento das informações utilizamos como metodologia a análise de conteúdo (BARDIN 2016).

A técnica de Grupo Focal viabilizou a interação e as relações entre as participantes, permitindo trocas de experiências entre elas. Apresentaram sugestões e ideias, sempre em situações de tentativa e erro, entendendo o "erro" como uma oportunidade de aprendizado e de transformação das concepções que temos de escola (HADJI, 2001). Por meio da análise de conteúdo (BARDIN, 2016), aos poucos percebemos os anseios, as pretensões, os desejos das participantes em propor avaliações que pudessem, de fato, incluir as crianças.

Muitas professoras buscam procedimentos diferenciados, a fim de contribuir com o processo educativo, tendo em vista as necessidades educacionais específicas das crianças com deficiências. Nas discussões, percebemos que as professoras destacam a função da escola frente ao trabalho pedagógico com crianças com deficiência.

Nos fundamentamos em documentos legais como a Lei de Diretrizes e Bases da Educação, n 9394/1996 (BRASIL, 1996), na Lei nº 13.146/2015 (BRASIL, 2015), na Política Nacional de Educação Especial na Perspectiva da Educação Inclusiva (BRASIL, 2008), na Portaria $n^{\circ}$ 948/2007 (BRASIL, 2008), nas Diretrizes Nacionais para a Educação Especial na Educação Básica (BRASIL, 2001). Além disso, nos pautamos em autores e autoras que pesquisam este assunto como: Carvalho (2010), Rodrigues (2006), Pacheco (2008), Glat (2009), Mantoan (2006), entre outros. Usamos a concepção de avaliação formativa como opção ideológica nos apoiando em Fernandes (2006; 2009; 2011), Freitas (1991; 1995; 2003), Hadji (2001), Haydt (2004), Hoffmann (2001; 2003; 2018) Luckesi (2008; 2018), Villas Boas $(2011 ; 2012 ; 2013 ; 2017)$, entre outros.

Nesta discussão teórica, aprofundamos também em autores e autoras da Educação Especial que trouxeram reflexões sobre a avaliação escolar no contexto da área, como Teixeira e Nunes (2010), Beyer (2013), Oliveira e Manzini (2016), Jesus (2015) e outros. A ênfase dada pelos seus estudos está relacionada à: a) procedimentos e a condução das práticas pedagógicas; b) respeitar o tempo e o ritmo de cada criança; c) compreender as limitações e, d) optar por considerar as potencialidades e possibilidades.

Deste modo, a análise de conteúdo, segundo Bardin (2016), concentrou-se em eixos temáticos obtidos a partir das discussões dos grupos focais realizados e do questionário aplicado. Na categorização dos eixos temáticos selecionamos: 1 - Concepções de avaliação, aproximações da avaliação formativa e impactos das concepções de avaliação no trabalho 
com as crianças com deficiências; 2 - Propostas de trabalhos avaliativos; 3 - Processo educacional das crianças com deficiências.

A pesquisa foi registrada no Comitê de ética sob o Parecer de número 3.234.343.

\section{Resultados da pesquisa}

Nossa pesquisa contou com o número limitado de 24 participantes. No entanto acreditamos que esse grupo representou, simbolicamente, com muita sensibilidade e disposição, as vozes de muitas outras professoras que discutem educação, escola, docência, avaliação, deficiência, trabalho pedagógico e criança. Destacamos que as professoras participantes da pesquisa se mostraram motivadas durante o grupo focal, em busca de respostas, sugestões, soluções e possibilidades para efetivar processos avaliativos escolares diferente daqueles vivenciados hoje em dia, nas escolas.

Nas sessões de grupo focal, o assunto girou em torno dos desafios da inclusão escolar, o caminho político e histórico da Educação Especial até o momento e os enfrentamentos por parte das famílias e escolas na implementação de uma inclusão escolar que não seja perversa ou apenas um 'faz de conta' para as crianças com deficiências.

Acreditamos que as professoras participantes enunciaram muitas angústias, frustrações, sentimentos e impotências frente aos contextos. Mas, verificamos também, que elas expressaram corajosamente propostas de trabalhos adaptadas, experiências fidedignas, ensaios, ponderações, tentativas, expectativas e ações de "esperançar" em favor da aprendizagem de crianças com deficiência.

As análises dos dados demonstram que as professoras apresentam concepções diferentes sobre avaliação entre o que acreditam e o que é desenvolvido nas escolas. Muitas destacam "a prova" como o procedimento predominante na hora de avaliar as crianças com deficiência, no entanto, criticam essa escolha e não concordam que este seja o caminho. Revelam que a avaliação na escola não se constitui em um processo, mas ocorre em momentos específicos de processo-produto, prova-nota. As professoras ainda apontam que avaliações conduzidas desta maneira interrompem as ações cotidianas já planejadas e organizadas, que poderiam favorecer a aprendizagem das crianças com deficiências.

As professoras denunciam as exigências burocráticas do sistema de notas escolares, enfatizando que não favorecem o desenvolvimento das aprendizagens das crianças. Ao mesmo tempo, as próprias professoras desabafam que essas exigências geram sentimentos de preocupação, opressão e tristeza para elas e sentem que, para as crianças, causam frustração, 
desencantamento e sentimento de fracasso, pois estas se tornam vítimas de um sistema imposto e excludente.

Além disso, ressaltam as reivindicações de famílias quanto à aprovação e/ou reprovação, indicando que essa demanda não auxilia no desenvolvimento escolar das crianças com deficiência. Apareceram nos diálogos exemplos que demonstraram a prioridade que algumas professoras percebiam na condução do trabalho pedagógico com as crianças, antecedendo o ensino de conteúdos e, especialmente, o estabelecimento de notas escolares. Algumas participantes também relataram situações que viveram em que o saber das crianças foi desprezado, especialmente quando houve uma exigência em padronizar todos os saberes sob uma ótica excludente.

Notamos que as participantes compreendem a avaliação em uma perspectiva diferente, pois salientam a necessidade de dedicar tempo para planejar, elaborar, aplicar novas práticas pedagógicas e consequentemente outras propostas avaliativas. Elas reconhecem que os resultados alcançados no cotidiano da sala de aula têm mais valor do que um procedimento avaliativo que apenas mensura e classifica.

Exemplificam outras possibilidades, como: avaliação durante o processo; portfólio; autoavaliação; seminários; GV-GO (grupo de verbalização/grupo de observação); observação: diária, semanal, individual e/ou em grupos, da participação e interesse, do desenvolvimento, do comportamento, da interação; entrevistas; conversa informal; relatórios de desenvolvimento; atividades diversificadas; valorização das produções realizadas; mediação professor-estudante (com uso de materiais); fichas avaliativas; entre outros.

Para corroborar com essas sugestões, Hoffmann (2018) deixa claro a importância da observação atenta com registros específicos mediados por um trabalho pedagógico que atenda a necessidade de cada um, segundo sua singularidade. Segundo o autor,

É preciso 'aprender a olhar' aluno por aluno, conhecendo seu espaço de vida, suas iniciativas, seu fazer de novo, seus afetos e desafetos, dissonâncias, o inusitado muitas vezes (HOFFMANN, 2018, p. 58-59).

As professoras demonstraram intenções de transformar as práticas avaliativas. Constatamos alguns ensaios que se aproximam da concepção da avaliação formativa, especialmente quando exemplificam propostas de avaliação que procuram atender a possibilidade de aprendizagem das crianças com deficiências, mesmo que ainda não seja uma ação predominante no cotidiano. 
Para o processo educacional das crianças com deficiência, as professoras entendem que é necessário ensinar-aprender; avaliar-reavaliar; planejar-replanejar, estabelecer objetivos e critérios, os alcançar e realinhar novas ações. Desta maneira, percebemos sensibilidade e esforço ao organizar o trabalho didático-pedagógico e avaliativo para alcançar a aprendizagem. Por esse motivo a avaliação formativa "[...] é um processo social, pedagógico e político que coloca todos/as em condições para aprender". Implica um processo de ir e vir do conhecimento; implica aprender e ensinar, tanto para o/a estudante, quanto para o/a docente. É um processo de dialogicidade que ocorre entre as paredes da sala de aula, inclusive fora dela, cotidianamente (MENDES et al., 2018, p. 84, 85).

As professoras promovem o aprendizado das crianças com deficiência quando modificam sua forma de ensinar. Assim, acreditamos que tanto as crianças, quanto as professoras são beneficiadas pela tríade educacional: ensino, aprendizagem e avaliação, tornando a escola menos excludente (FREITAS, 2003).

Neste sentido, constatamos que há intenção, por parte das professoras em desenvolver o trabalho pedagógico na perspectiva da avaliação formativa, mesmo que ainda não se deem conta disso, uma vez que estão decididas a colocar a avaliação a serviço da aprendizagem da criança, buscando todas as formas possíveis para agir neste sentido (HADJI, 1994).

Consideramos nos relatos das professoras, que suas ações se aproximam dos princípios de uma avaliação formativa, quando:

- entendem e percebem a necessidade de mudanças nas próprias atitudes e pensamentos ao planejar as avaliações escolares;

- optam por organizar o trabalho pedagógico de modo a contemplar o desenvolvimento humano, observando com atenção e sensibilidade;

- buscam práticas de avaliação que compreendam a criança com deficiência em suas potencialidades;

- adaptam os recursos didático-pedagógicos para aplicar as avaliações observando as singularidades de cada caso;

- levam em conta o tempo e o ritmo de desenvolvimento de cada criança com deficiência que atendem;

- flexibilizam os conteúdos, priorizando aqueles que são mais significativos para a criança, demonstrando preocupação com o ensino e com a aprendizagem;

- corresponsabilizam todos da comunidade escolar e familiar, na intenção de garantir o pleno desenvolvimento das crianças, e; 
- realizam propostas de trabalho avaliativas diferenciadas, que podem promover os ajustes no processo de ensino-aprendizagem.

Escolhemos a avaliação formativa pois acreditamos que ela é capaz de transformar o modo como a escola encara a avaliação, estabelecendo práticas escolares avaliativas mais inclusivas. Entendemos que a avaliação formativa favorece a organização do trabalho pedagógico com o foco para aprendizagem; oferece visibilidade aos resultados alcançados no cotidiano da sala de aula; e se preocupa em diversificar as propostas de trabalho, com intuito de assegurar de todas as maneiras possíveis a aprendizagem.

Destacamos que nos arquivos oficiais analisados encontramos o incentivo a estudos e formações contínuas para aprimoramento e aperfeiçoamento das práticas escolares e ações que promovem a articulação do trabalho pedagógico entre as professoras, tanto da sala regular quanto do Atendimento Educacional Especializado (AEE). Assim como indícios que sugerem o fortalecimento de práticas da avaliação formativa, como por exemplo: o trabalho coletivo; coparticipação das famílias e de outros profissionais no processo de avaliação das crianças; respeito à pessoa e sua singularidade; entre outros.

Evidentemente, entendemos que a avaliação escolar com foco na aprendizagem ainda está longe de ser uma realidade para todos/as os/as estudantes, quanto mais para as crianças com deficiência. Isso acontece porque a sociedade em que vivemos perpetua os interesses do capital e afasta a possibilidade de uma escola inclusiva que realmente ensine, na qual todas as crianças aprendam. No resgate conceitual de Inclusão Escolar percebemos o quanto é desafiador para a escola, em uma dimensão macro, promover acessibilidade para vencer as barreiras arquitetônicas, atitudinais, urbanísticas, tecnológicas, de comunicação, entre outras que interferem na organização do trabalho pedagógico. Constatamos na pesquisa o quanto a avaliação escolar ainda é conduzida de forma hierárquica, com caráter seletivo e classificatório.

A avaliação ainda é excludente! Por isso a necessidade de efetivar mudanças significativas nas práticas avaliativas escolares, uma vez que inclusão não é o interesse dessa sociedade competitiva, em que não há espaço para todas as pessoas. Conforme afirma Freitas (2003, p. 13-30), “[...] a escola é uma construção histórica [...] não foi o professor que inventou essa lógica, ela faz parte da gênese da escola". No entanto, valorizamos, reconhecemos e respeitamos que as ações das professoras participantes em nossa pesquisa, caminham para um movimento de resistência. 
Ainda, ressaltamos a importância de revisitar documentos oficiais em âmbito federal, estadual e municipal que apresentam sugestões de procedimentos para avaliação escolar. Esses documentos indicam que o procedimento da observação diária é um importante aliado no processo de avaliação para crianças com deficiência, também apontam a diversificação das atividades nas dimensões cognitivas, afetivas, sensoriais e sociais.

\section{Considerações finais}

Podemos dizer que, a pesquisa realizada nos leva a crer que as crianças com deficiência são beneficiadas em seus processos educativos: a) quando todos/as se comprometem com sua escolarização; b) quando as professoras resistem ao sistema e buscam meios de estabelecer outras formas de avaliar; c) quando o coletivo se corresponsabiliza, cria e aplica propostas de trabalho avaliativo que considera as necessidades educacionais específicas das crianças, favorecendo o movimento de inclusão.

Pensar e realizar a avaliação formativa para crianças com deficiência é rebelar-se contra o sistema capitalista e burocrático e fazer da aprendizagem o foco da escola. Ao analisar as concepções das professoras sobre avaliação escolar, os impactos da inclusão escolar sobre a avaliação para as crianças com deficiência e os conhecimentos dos/as professores/as sobre avaliação formativa, nos deparamos com os sentimentos e desejos de mudança que geram intenções de transformação, resistência e esperança.

Percebemos que as professoras se esforçam em organizar outras maneiras de avaliar, esquivando-se da lógica capitalista, excludente e massificante da escola. Notamos o quanto é complexo e difícil conduzir o trabalho pedagógico com e para as crianças com defíciência. Sabemos que transformar o processo de avaliação na escola é um desafio constante para todos/as, pois requer mudanças de concepções sobre o que entendemos por pessoa, ensino, aprendizagem, avaliação, tempo, recursos, procedimentos, entre outros, nos processos educacionais. Requer que procuremos outros caminhos que atendam às necessidades educacionais específicas das crianças com deficiência, comprometidos com o princípio de avaliar para as aprendizagens.

Somos otimistas em reconhecer que as mudanças estão acontecendo, aos poucos, mas estão acontecendo! Não há como nos esquivar dos paradigmas emergentes relacionados à inclusão escolar e a avaliação das crianças com deficiência. Por este motivo, reconhecemos nas perspectivas da maioria das participantes: a) que cada ser é único, singular e necessita de um olhar sensível e específico em seu processo educativo e avaliativo; b) que a intenção em 
avaliar para as aprendizagens é primordial; c) que estabelecer vínculos e conhecer as necessidades educacionais específicas é essencial para garantir as aprendizagens significativas das crianças com deficiências; d) que muitas vezes é preciso diversificar as propostas de trabalho avaliativo, modificando as metodologias e os modos de organizar o trabalho pedagógico para atender as crianças em suas singularidades; e) que pensar o ensino requer uma outra concepção de criança, de estudante, de pessoa e de ensino-aprendizagem; f) que o caminho é flexibilizar os saberes e conteúdo, priorizando aqueles em que as crianças com deficiências podem ter melhores condições e possibilidades para aprender e; g) que a corresponsabilização de toda a comunidade escolar é fundamental para o desenvolvimento das crianças com deficiências em seu processo educacional.

Ressaltamos que viver e praticar a avaliação formativa não é fácil. Sabemos que ainda há uma longa trajetória a seguir, pois "romper com o estigma classificatório da avaliação" não é responsabilidade apenas da escola, mas da sociedade como um todo. Vamos caminhando, um passo de cada vez, pois não há como acelerar o passo, ou vamos juntos, ou não chegaremos a lugar algum. Assim como destacam Mantoan e Baptista (2018, p. 764): "Formar pessoas para o ensino inclusivo foi uma oportunidade de criarmos e de colocarmos em prática novas maneiras de ensinar sem discriminações, nunca antes propiciadas por uma política pública escolar".

Em síntese, acreditamos que esses apontamentos amparam nossa certeza, que o caminho percorrido até agora nos revelou as aproximações entre as práticas das professoras e os princípios da avaliação formativa, contribuindo assim, no processo educacional das crianças com deficiência.

Defendemos uma perspectiva de avaliação inclusiva, aquela que estabelece uma reflexão coletiva entre professores/as, estudantes e familiares e proporciona um processo de aprender e ensinar considerando as singularidades de cada um/a. Assim, entendemos que a avaliação escolar precisa transcender os sistemas vigentes. Buscar novos meios de compreendermos a nós mesmos, a sociedade da qual fazemos parte e, mesmo, a sociedade que almejamos. Enquanto coletivo plural e docentes, majoritariamente mulheres, resistir e lutar para organizar mecanismos que materializem novos sistemas escolares inclusivos que permitam a aprendizagem significativa de todas as pessoas no contexto escolar. 


\section{REFERÊNCIAS}

BARDIN, L. Análise de conteúdo. Trad. Luís Antero Reto, Augusto Pinheiro. São Paulo: Edições 70, 2016.

BEYER, H. O. Inclusão e avaliação na escola: de alunos com necessidades educacionais especiais. 4. ed. Porto Alegre: Mediação, 2013.

BOGDAN, R.; BIKLEN, S. K. Investigação qualitativa em educação: uma introdução à teoria e aos métodos. Porto, Portugal: Porto Editora, 1994.

BRASIL. A inclusão escolar de alunos com necessidades educacionais especiais. Brasília, DF: MEC, 2006. Disponível em: http://portal.mec.gov.br/seesp/arquivos/pdf/deffisica.pdf. Acesso em: 15 jan. 2020.

BRASIL. Conselho Nacional da Educação. Parecer CNE/CEB n. 13/2009. Institui Diretrizes Operacionais para o Atendimento Educacional Especializado na Educação Básica, modalidade Educação Especial. Brasília, DF: CNE, 2009. Disponível em: http://portal.mec.gov.br/dmdocuments/rceb004_09.pdf. Acesso em: 12 maio 2020.

BRASIL. Conselho Nacional da Educação. Resolução CNE/CEB n. 2, de 11 de setembro de 2001. Institui Diretrizes Nacionais para a Educação Especial na Educação Básica. Brasília, DF: CNE, 2001. Disponível em: http://portal.mec.gov.br/arquivos/pdf/resolucao2.pdf. Acesso em: 12 maio 2020.

BRASIL. Decreto n. 7.611, de 17 de novembro de 2011. Dispõe sobre a educação especial, o atendimento educacional especializado e dá outras providências. Brasília, DF: MEC/SEESP, 2011. Disponível em: http://www.planalto.gov.br/ccivil_03/_ato20112014/2011/decreto/d7611.htm. Acesso em: 10 out. 2019.

BRASIL. Lei n. 9394/96, de 20 de dezembro de 1996. Estabelece as diretrizes e bases da educação nacional. Brasília, DF: Presidência da República, 1996. Disponível em: http://www.planalto.gov.br/ccivil_03/leis/19394.htm. Acesso em: 10 out. 2019.

BRASIL. Secretaria de Educação Especial. Política nacional de educação especial na perspectiva da educação inclusiva. Brasília, DF: MEC/SEESP, 2008.

CARVALHO, R. E. Removendo as barreiras para a aprendizagem: educação inclusiva. 9. ed. Porto Alegre: Mediação, 2010.

FERNANDES, D. Articulação da aprendizagem, da avaliação e do ensino: questões teóricas, práticas e metodológicas. In: ALVES, M. P.; KETELE, J. M. (Org.). Do currículo à avaliação, da avaliação ao currículo. Porto: Porto Editora, 2011. p. 131-142.

FERNANDES, D. Avaliar para aprender: fundamentos, práticas e políticas. São Paulo. Editora UNESP, 2009.

FERNANDES, D. Para uma teoria da avaliação formativa. Revista Portuguesa de Educação [online], Braga, v. 19, n. 2, p. 21-50, 2006. Disponível em: 
http://www.scielo.mec.pt/scielo.php?script=sci abstract\&pid=S0871-

$91872006000200003 \& \operatorname{lng}=$ es\&nrm=.pf. Acesso em: 10 out. 2019.

FREITAS, L. C. Ciclos, seriação e avaliação: confronto de lógicas. São Paulo: Moderna, 2003.

GLAT, R. Educação inclusiva: cultura e cotidiano escolar. Rio de Janeiro: 7 Letras, 2009.

GONDIN, S. M. G. Grupos Focais como técnica de investigação qualitativa: desafios metodológicos. Revista Paideia, Ribeirão Preto, v. 12, n. 24, 2003.

HADJI, C. Avaliação desmistificada. Porto Alegre. Artmed, 2001.

HAYDT, R. C. C. Avaliação do processo ensino-aprendizagem. 6. ed. São Paulo. Ática, 2004.

HOFFMAN, J. Avaliação mito e desafio: uma perspectiva construtiva. Porto Alegre:

Mediação, 2003.

HOFFMAN, J. Avaliar para promover. Porto Alegre: Mediação, 2001.

HOFFMAN, J. O jogo do contrário em avaliação. 10. ed. Porto Alegre: Mediação, 2018.

JESUS, D. M. et al. Avaliação e educação especial: diálogos sobre diagnóstico, planejamento e rendimento escolar nas salas de recursos multifuncionais. In: JESUS, D. M.; VICTOR, S. L.; GONÇALVES, A. F. S. (Org) Formação, práticas pedagógicas e inclusão escolar no observatório estadual da educação especial. São Carlos: ABPEE, 2015. p. 93-114.

LUCKESI, C. C. Avaliação da aprendizagem escolar: estudos e proposições. 19. ed. São Paulo. Cortez, 2008.

LUCKESI, C. C. Avaliação em educação: questões epistemológicas e práticas. 1. ed. São Paulo: Cortez, 2018.

MANTOAN, M. T. E. Inclusão escolar: O que é? Por quê? Como fazer? 2. ed. São Paulo: Moderna, 2006.

MANTOAN, M. T. E.; BAPTISTA, M. I. S. D. Inovar para fazer acontecer: como estamos fortalecendo redes de apoio à educação inclusiva. Revista on line de Política e Gestão Educacional, Araraquara, v. 22, n. esp. 2, p. 763-777, dez. 2018. ISSN: 1519-9029. DOI: https://doi.org/10.22633/rpge.unesp.v22.nesp2.dez.2018.11911

MENDES, O. M. M.; RICHTER, L. M.; MARTINS, C. A.; CAMARGO, C. C. O.; COSTA, S. F. P. (Org.). Pesquisa coletiva, avaliação externa e qualidade da escola pública. 1. ed. Curitiba: CRV, 2018.

OLIVEIRA, C. C. B; MANZINI, E. J. Encaminhamento e perfil do público-alvo da educação especial de uma sala de recursos multifuncionais: estudo de caso. Revista Brasileira de Educação Especial, Marília, v. 22, n. 4, p. 559-576, out./dez. 2016. DOI: https://doi.org/10.1590/s1413-65382216000400007 
RODRIGUES, D. Inclusão e educação: doze olhares sobre a educação inclusiva. São Paulo: Summus, 2006.

TEIXEIRA, J.; NUNES, L. Avaliação inclusiva: a diversidade reconhecida e valorizada. Rio de Janeiro: Wak Editora, 2010.

VILLAS BOAS, B. M. F. Avaliação formativa: práticas inovadoras. 1. ed. Campinas, SP. Papirus, 2011

VILLAS BOAS, B. M. F. Avaliação: interações com o trabalho pedagógico. 1. ed. Campinas, SP: Papirus, 2017

VILLAS BOAS, B. M. F. Portifólio, avaliação e trabalho pedagógico. 8. ed. Campinas, SP. Papirus, 2012.

VILLAS BOAS, B. M. F. Virando a escola pelo avesso por meio da avaliação. 2. ed. Campinas, SP: Papirus, 2013.

\section{Como referenciar este artigo}

PEIXOTO, J. C. G.; MENDES, O. M. Avaliação escolar e as crianças com deficiências: de políticas excludentes a aproximações inclusivas. Revista on line de Política e Gestão Educacional, Araraquara, v. 25, n. 1, p. 06-18, jan./abr. 2021. e-ISSN:1519-9029. DOI: https://doi.org/10.22633/rpge.v25i1.14113

Submetido em: $31 / 08 / 2020$

Revisões requeridas em: 10/09/2020

Aceito em: 01/11/2020

Publicado em: 02/01/2021 